\title{
Intestinal Metaplasia of Columnar Epithelium
}

National Cancer Institute

\section{Source}

National Cancer Institute. Intestinal Metaplasia of Columnar Epithelium. NCI Thesaurus. Code 196170.

A morphologic finding indicating the replacement of part of the columnar epithelium by intestinal-type epithelium. 